\title{
REGULADORES VEGETAIS INFLUENCIANDO NÚMERO E TAMANHO DE CÉLULAS DAS BAGAS DA UVA 'NIAGARA ROSADA'
}

\author{
CÁSSIA REGINA YURIKO IDE VIEIRA², ERASMO JOSÉ PAIOLI PIRES ${ }^{3}$, MAURILO MONTEIRO TERRA $^{3}$, \\ MARCO ANTONIO TECCHIO ${ }^{4}$, MARIA DO CARMO VIEIRA ${ }^{5}$.
}

RESUMO - O objetivo do trabalho foi avaliar o efeito do ácido giberélico, thidiazuron e quinmerac na anatomia das bagas de uvas cultivar 'Niagara Rosada', provenientes de vinhedo localizado em Dourados - MS. Realizaram-se três experimentos. No primeiro ensaio, utilizaram-se soluções aquosas de ácido giberélico $\left(\mathrm{AG}_{3}\right) 0 ; 15 ; 30 ; 45 ; 60 ; 75$ e $90 \mathrm{mg} .1^{-1}$, aplicadas no florescimento e repetidas aos 14 dias após (E1E2) e, no outro tratamento, o mesmo composto e doses aplicados uma única vez aos 14 dias após o florescimento (E2); no segundo experimento, thidiazuron (TDZ) $0 ; 5 ; 10 ; 15 ; 20 ; 25$ e $30 \mathrm{mg} . .^{1-1}$, aplicados quatro dias antes da antese e repetidos aos seis dias após o florescimento (E1E2); e no outro tratamento, o mesmo composto e doses aplicados uma única vez aos seis dias após o florescimento (E2); e, no terceiro, quinmerac $0 ; 10 ; 20 ; 30 ; 40 ; 50$ e $60 \mathrm{mg} .1^{-1}$, aplicados no florescimento e repetidos aos 14 dias após (E1E2), e, no outro tratamento, o mesmo composto e doses aplicados uma única vez, 14 dias após o florescimento (E2). As variáveis avaliadas foram: número e dimensões das células das bagas. Pelos resultados obtidos, verificou-se que duas aplicações de ácido giberélico, thidiazuron e quinmerac promoveram a divisão celular, enquanto a expansão celular foi observada com uma única aplicação de thidiazuron e quinmerac.

Termos para indexação: Videira, Vitis, regulador vegetal, anatomia, auxina, giberelina, citocinina.

\section{PLANT REGULATORS INFLUENCING NUMBER AND SIZE OF BERRY CELLS OF 'NIAGARA ROSADA' GRAPES}

\begin{abstract}
The objective of this investigation was to evaluate the effect of the gibberellic acid, thidiazuron and quinmerac on grape berries anatomy of grapevine 'Niagara Rosada', in a vineyard located in Dourados - MS. Three trials were carried out. In the first trial, it was used gibberellic acid $\left(\mathrm{AG}_{3}\right) 0,15,30,45,60,75$ and $90 \mathrm{mg} \cdot \mathrm{l}^{-1}$, applied in the bloom and repeated 14 days later (E1E2) and in the other treatment, the same compound and doses applied only once, 14 days after the bloom (E2); in the second experiment, thidiazuron (TDZ) $0,5,10,15,20,25$ and $30 \mathrm{mg} . \mathrm{l}^{-1}$, applied four days before antesis and repeated six days after the bloom (E1E2); and in the other treatment, the same compound and doses applied only once six days after the bloom (E2); and in the third, quinmerac 0, 10, 20, 30, 40, 50 and $60 \mathrm{mg} . \mathrm{l}^{-1}$, applied in the bloom and repeated 14 days after (E1E2) and in the other treatment, the same compound and doses applied only once 14 days later the bloom (E2). The plant regulators were applied through cluster dipping with surfactant Agral ${ }^{\circledR}, 1 \%$ added to solutions. The variables evaluated were: berries cells number and dimensions. From the obtained results, it was observed that two applications of gibberellic acid, thidiazuron and quinmerac promoted the cellular division, while the cellular expansion was observed with only one application of thidiazuron and quinmerac.
\end{abstract}

Index Terms: grapevine, Vitis, plant regulator, anatomy, auxin, gibberelin, cytokinin.

\section{INTRODUÇÃO}

Os reguladores vegetais têm sido utilizados em videiras para aumentar o tamanho e melhorar a qualidade das bagas e cachos, incrementar a fixação de frutos, a supressão de sementes, acelerar ou retardar a maturação de frutos, estimular o enraizamento de estacas e uniformizar a brotação de gemas, controlar o crescimento vegetativo e aumentar a fertilidade de gemas (Pires \& Botelho, 2001).

No Estado de Mato Grosso do Sul, a viticultura encontrase em processo de expansão. No entanto, as uvas produzidas não vêm alcançando padrão satisfatório, com bagas e cachos pequenos e malformados, acarretando em problemas na comercialização, necessitando, portanto, de técnicas agronômicas para otimizar a qualidade e produções. Dessa forma, o emprego de reguladores vegetais surge como alternativa viável, podendo levar a modificações qualitativas e quantitativas na produção e tornando a atividade economicamente rentável.

Além de alterações morfológicas, verificam-se também modificações anatômicas nas bagas de uva. As mudanças estruturais ocorridas na planta estão associadas a mudanças metabólicas. As giberelinas estimulam a divisão e o alongamento celular, podendo promover o crescimento de órgãos vegetais pelo aumento do tamanho de células já existentes ou recentemente

'(Trabalho 084-07). Recebido em: 28-03-2007. Aceito para publicação em: 19-09-2007. Parte da Tese de Doutorado da primeira autora, Curso de pós graduação em Agronomia da FCA- UNESP, campus de Botucatu - SP.

${ }^{2}$ Eng. Agr., Dra, Pesquisadora científica da AGRAER/MS, Rua General Osório, 3100. CEP 79 824-060, Dourados, MS, e-mail - cvieira@agraer.ms.gov.br. ${ }^{3}$ Eng. Agr, Dr, Pesquisador científico, Instituto Agronômico de Campinas, Avenida Barão de Itapura, 1481, Campinas - SP, 13.001-920, e-mail: ejppires@iac.sp.gov.br; mmterra@iac.p.gov.br.

${ }^{4}$ Eng. Agr, Dr, Pesquisador Científico, Centro APTA Frutas do Instituto Agronômico de Campinas. Av. Luiz Pereira dos Santos, 1500, Bairro Corrupira 13214-820 - Jundiaí - SP, email - tecchio@iac.sp.gov.br

${ }^{5}$ Eng. Agr., Dra., Profa. titular da Faculdade de Ciências Agrárias da UFGD, Caixa Postal 533, CEP 79.804-970. Dourados - MS, e-mail: vieiracm@terra.com.br. 
divididas (Davies, 1988; Métraux,1988). Há evidências de que a enzima xiloglucano endotransglicosilase (XET) esteja envolvida na extensão da parede, porque facilita a entrada de expansinas, que, por sua vez, promovem o rompimento das ligações de hidrogênio entre os polissacarídeos (Taiz \& Zeiger, 2004). Como conseqüência, há aumento da elasticidade da parede celular, com entrada de água e alongamento celular. Supõe-se que um dos mecanismos pelos quais as giberelinas podem estimular a expansão celular, seja a hidrólise do amido, resultante da produção de $\alpha$-amilase gerada, incrementando a produção de açúcares e elevando a pressão osmótica do suco celular, e, dessa forma, permitindo a entrada de água (Pires \& Botelho, 2001).

Wu et al. (2001) verificaram em videiras 'Fujiminori' que aplicações de ácido giberélico induziram aumento do número e do volume de células, resultando em aumento nas dimensões e na massa fresca e seca dos frutos.

Sarig et al. (1998) verificaram em videiras 'Sultanina' que $40 \mathrm{mg} . \mathrm{l}^{-1}$ de ácido giberélico, aplicados em bagas com 3 a $4 \mathrm{~mm}$ de diâmetro, induziram aumento do tamanho das células da epiderme, particularmente na hipoderme.

As citocininas são substâncias derivadas da purina adenina as quais promovem a divisão celular, a mobilização de nutrientes, a formação e a atividade dos meristemas apicais, o desenvolvimento floral, a germinação de sementes, a quebra de dormência de sementes e gemas, alongamento celular, desenvolvimento de frutos, hidrólise de reservas de amido, retardo da senescência e dominância apical (Wareing \& Phillips, 1976; Ludford, 1987; Davies, 1988; Taiz \& Zeiger, 2004). São sintetizadas na raiz e transportadas via xilema para outras partes da planta (Taiz \& Zeiger, 2004). Tem sido sugerido que a citocinina estimula a mobilização de nutrientes, por criar uma forte relação fontedreno, fazendo com que haja a concentração de nutrientes, em função de maior vascularização nessa região (Taiz \& Zeiger, 2004; Guardiola et al., 1993), bem como inibe sua saída das áreas tratadas (Metivier, 1985).

O thidiazuron (N-fenil-N'-1,2,3-tiadiazol-5-ilurea), uma feniluréia do mesmo grupo do forclorfenuron, é um regulador de crescimento que apresenta ação semelhante à citocinina. (Henny e Fooshee, 2002), sendo dez mil vezes mais potente que a benzilaminopurina (Meyer \& Kernsh, 1986).

Em estudos morfológicos, verificou-se não apenas o aumento do número de células, mas também que a expansão celular foi responsável pelo crescimento dos frutos de kiwi tratados com CPPU (Blank et al., 1992; Antognozzi et al., 1997). O crescimento dos frutos foi associado apenas ao número de células, em maçãs (Rao et al., 1999; Costa et al., 2001; Stern et al., 2003) e peras (Hirata \& Higano, 1987).

As auxinas aumentam a extensibilidade da parede celular, promovem a divisão celular, o crescimento das folhas e da raiz, e regula o desenvolvimento dos frutos (Taiz \& Zeiger, 2004; Valio, 1985).

Um grande número de auxinas sintéticas já foi produzido em laboratório, como as substâncias endólicas, os derivados dos ácidos fenoxiacéticos e ácido benzóico, e os tiocarbamatos. As auxinas sintéticas são bastante eficientes, pois não são metabolizadas pelas plantas tão rapidamente quanto o AIA (Taiz
\& Zeiger, 2004).

O efeito da aplicação de auxina sintética no crescimento das bagas de uva depende do tipo do regulador, da dose e época de aplicação e características da cultivar. O ácido 4-cloro fenoxiacético aplicado após o pegamento dos frutos, em cultivares sem sementes, aumenta o crescimento das bagas e retarda a maturação. Imersão dos cachos, em plena florada, em soluções a baixas concentrações de ácido 2,4 diclorofenoxiacético, reduz ligeiramente o número de sementes e promove o acúmulo de açúcares (Kanellis \& Roubelakis-Angelakis, 1993).

Quinmerac ou IUPAC (ácido 7-cloro-3-metilquinolina-8carboxílico) é um regulador vegetal que apresenta modo de ação semelhante à auxina. Promove a expansão celular em bulbos e frutos; auxilia no transporte de assimilados no interior da planta, resultando em frutos maiores e mais pesados (Pires \& Botelho, 2001). Esse produto tem sido bastante utilizado em citros para promover o aumento do tamanho dos frutos. Rodríguez et al. (2000) verificaram incrementos no tamanho de frutos de tangerinas Clementina com o uso do quinmerac.

O objetivo deste trabalho foi avaliar os efeitos da aplicação de ácido giberélico, thidiazuron e quinmerac, em diferentes doses e épocas, na anatomia das bagas de uva cultivar Niagara Rosada.

\section{MATERIAL E MÉTODOS}

O experimento foi conduzido no vinhedo de produtor localizado no Município de Dourados - MS, durante o período de julho de 2003 a fevereiro de 2004. A cultivar utilizada foi Niagara Rosada, enxertada sobre o porta enxerto IAC 572 'Jales', conduzida em sistema de latada, em espaçamento de $2,5 \mathrm{~m}$ x 2,0m, no $3^{\circ}$ ano de produção.

Realizaram-se três experimentos. No primeiro ensaio, utilizaram-se soluções aquosas de ácido giberélico $\left(\mathrm{AG}_{3}\right) 0 ; 15$; $30 ; 45 ; 60 ; 75$ e $90 \mathrm{mg}^{-1^{-1}}$, aplicadas no florescimento e repetidas aos 14 dias após (E1E2), e, no outro tratamento, o mesmo composto e doses aplicados uma única vez, aos 14 dias após o florescimento (E2); no segundo experimento, thidiazuron (TDZ) $0 ; 5 ; 10 ; 15 ; 20$; 25 e $30 \mathrm{mg} \cdot \mathrm{l}^{-1}$, aplicados quatro dias antes da antese e repetidos aos seis dias após o florescimento (E1E2); e, no outro tratamento, o mesmo composto e doses aplicados uma única vez aos seis dias após o florescimento (E2); e, no terceiro, quinmerac $0 ; 10 ; 20$; $30 ; 40 ; 50$ e $60 \mathrm{mg} .1^{-1}$, aplicados no florescimento e repetidos aos 14 dias após (E1E2), e, no outro tratamento, o mesmo composto e doses aplicados uma única vez, 14 dias após o florescimento (E2).

Os tratamentos consistiram de sete doses e duas épocas de aplicação, arranjados como fatorial $7 \times 2$, no delineamento de blocos casualizados, com cinco repetições.

A colheita dos frutos foi efetuada quando os cachos atingiram ponto de colheita comercial, com teor de sólidos solúveis mínimo de $15^{\circ}$ Brix. Posteriormente, os cachos foram acondicionados em sacos de polietileno, devidamente identificados, transportados em caixas plásticas para a geladeira do Laboratório de Botânica da Faculdade de Agronomia da UFGD, onde foram mantidos à temperatura de $3^{\circ} \mathrm{C}$, durante o período de avaliação.

As variáveis avaliadas foram: número de células. $\mathrm{mm}^{-2} \mathrm{e}$ 
dimensões das células em $\mathrm{mm}^{2}$. A contagem do número de células do epicarpo foi realizada pela ocular de retículo, em 10 campos de cada porção do fruto, a saber: proximal, mediana e distal do pedicelo, num total de 30 campos/fruto. Foi analisado um fruto escolhido ao acaso, por repetição. Cada tratamento consistiu de cinco repetições, totalizando 150 campos por tratamento.

$\mathrm{O}$ fruto foi inicialmente fixado em FAA - formalina-acetoálcool $70 \%$, por 72 horas, e posteriormente conservado em álcool $70^{\circ} \mathrm{GL}$ (Johansen, 1940). No preparo do material, utilizaram-se as técnicas usuais de inclusão em parafina após desidratação em série alcoólica etílica (Johansen, 1940; Sass, 1951). No entanto, devido à textura da polpa fundente (Sousa, 1996), não foi possível efetuar os cortes histológicos com micrótomo. Desta forma, para as análises anatômicas, efetuaram-se secções longitudinais do epicarpo, nas porções proximal, mediana e distal do pedicelo, à mão livre, com auxílio de lâmina de barbear, as quais, a seguir, foram observadas ao microscópio. Com auxílio de câmara clara adaptada a um microscópio, foi avaliado o número de células $\mathrm{mm}^{-2}$.

Os dados obtidos foram submetidos à análise de variância. Quando o efeito de dose foi significativo, submeteram-se os dados à análise de regressão, até $5 \%$ de probabilidade.

\section{RESULTADOS E DISCUSSÃO}

O efeito dos reguladores vegetais sobre a anatomia dos frutos e a significância dos modelos de regressão estão apresentados na Tabela 1 .

Experimento 1 - Ácido giberélico $\left(\mathrm{AG}_{3}\right)$ 0; 15; 30; 45;

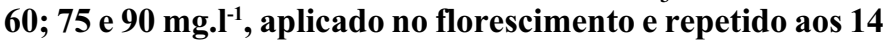
dias após (E1E2); e o mesmo composto aplicado uma única vez, aos 14 dias após o florescimento (E2).

Foi observado que o principal efeito do ácido giberélico foi a divisão celular. Verifica-se, na Figura 1A, que o número de células de bagas tratadas com ácido giberélico foi superior à testemunha. Constatou-se que a interação entre os fatores (época e dose) foi significativa para as variáveis: número de células.mm${ }^{2}$ e dimensão das células $\left(10^{-3} \mathrm{~mm}\right)$; no entanto, o número e a dimensão de células não foram influenciados pela época de aplicação do regulador. Para as duas variáveis, $\mathrm{o}_{3}$ teve efeito quadrático quando aplicado no florescimento e repetido aos 14 dias após (E1E2), e não-significativo para aplicações 14 dias após o florescimento (E2) (Tabela 1); considerando neste caso, para elaboração do gráfico, a média obtida em E2 (Figuras 1A e 1B). Para a E1E2, observou-se tendência de aumento máximo no número das células até a dose de $49 \mathrm{mg} . \mathrm{l}^{-1} \mathrm{de}_{\mathrm{AG}}$, seguido de diminuição nestes valores (Figura 1A). Verificou-se efeito oposto para a dimensão das células. As menores reduções na dimensão das células de $14 \%$, em relação à testemunha, foram obtidas com $\mathrm{AG}_{3}$ a $50 \mathrm{mg} \cdot \mathrm{l}^{-1}$ (Figura 1B). É conhecido o efeito das giberelinas na expansão e divisão celular (Taiz \& Zeiger, 2004). No entanto, constatou-se apenas o aumento do número, mas não da dimensão da célula. Observa-se, na Figura 1B, que a redução na dimensão foi compensada pelo maior número de células (Figura 1A). Aumentos no número de células também foram verificados por Hiratsuka et al. (1989), em videiras da cultivar Olímpia, tratadas com ácido giberélico. Jun et al. (2001) verificaram aumentos no número e no volume celular de bagas de uvas 'Fujiminori' tratadas com $25 \mathrm{mg} . \mathrm{l}^{-1}$ de ácido giberélico.

Embora ainda não sejam bem esclarecidos os mecanismos de ação das giberelinas nas plantas, este regulador atua no controle de vários processos metabólicos, entre os quais, a divisão celular, estimulando as células na fase $G_{1}$ a passar mais rapidamente para a fase S (Salisbury \& Ross, 1985). Sabe-se, no entanto, que os reguladores respondem a sinais específicos de amplo espectro ou longo alcance, para coordenar os arranjos no citoesqueleto, mas os receptores de ação desses reguladores ainda são desconhecidos (Daykin et al., 1997).

Experimento 2 - Thidiazuron (TDZ) 0; 5; 10; 15; 20; 25 e

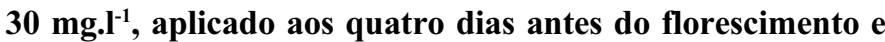
repetido aos seis dias após (E1E2); e o mesmo composto aplicado uma única vez, aos seis dias após a floração (E2).

Com relação ao thidiazuron, houve interação significativa entre os fatores para o número e dimensão das células (Tabela 1). $\mathrm{O}$ efeito fisiológico do thidiazuron na divisão celular foi evidenciado apenas quando aplicado aos quatro dias antes do florescimento e repetido aos seis dias após (E1E2); e a expansão celular, com uma única aplicação de TDZ, aos seis dias após o florescimento (E2) ( Tabela 1).

Metivier (1985) cita que a citocinina induz crescimento dos órgãos pela divisão e alongamento celular. A citocinina é responsável pela citocinese (divisão do citoplasma) durante o processo da divisão celular. Esse composto está ligado na abertura dos canais de cálcio da membrana plasmática, promovendo o aumento da concentração de cálcio no citoplasma, o qual é utilizado na síntese de pectatos de cálcio na parede celular e promovendo a expansão celular, e também atua como mensageiro secundário, promovendo a ativação de proteínas quinase e a ligação com a calmodulina (Srinivasan \& Mullins, 1980; Taiz \& Zeiger, 2004).

Constatou-se que a divisão celular foi mais intensa em E1E2, com aplicação de TDZ a $15 \mathrm{mg} . \mathrm{l}^{-1}$, apresentando valores de 403 células $\mathrm{mm}^{-2}$ (Figura 1C), o que significa aumento de 13\% em relação à testemunha. $\mathrm{O}$ oposto ocorreu quando se efetuou apenas uma aplicação de TDZ, em E2, sendo que os menores valores de números de células foram obtidos com TDZ a $30 \mathrm{mg} . \mathrm{l}^{-1}$, aplicado aos seis dias após o florescimento (E1E2). Verifica-se, na Figura $1 \mathrm{C}$, que as reduções do número de células observadas em E2 foram compensadas pelas maiores dimensões de células (Figura 1D). Sarig et al. (1998) também verificaram que aplicações de CPPU aumentaram a divisão celular em bagas, resultando em células menores, maior densidade de células e espessura na epiderme. Antognozzi et al. (1997) verificaram, em frutos de kiwi (cv Hayward), que o CPPU promoveu tanto a divisão, como a expansão celular, em células do pericarpo com diferentes dimensões: muito grande ou muito pequenas. Em trabalho semelhante, utilizando a mesma cultivar e regulador, Woolley et al. (1992) observaram que a divisão e expansão celular nos frutos ocorriam principalmente na parte mais externa do pericarpo.

Os valores estimados pela equação de regressão indicaram que incrementos de $15 \%$ nas dimensões de células foram obtidos com aplicações de TDZ a $30 \mathrm{mg}^{-1^{-1}}$. Para esta variável, não houve efeito significativo para a regressão linear e 
quadrática, considerando, neste caso, a média de E1E2 para elaboração do gráfico (Figura 1D).

Experimento 3 - Quinmerac 0; 10; 20; 30; 40; 50 e 60 mg. ${ }^{-1}$, aplicado no florescimento e repetido aos 14 dias após (E1E2); e o mesmo composto aplicado uma única vez, 14 dias após o florescimento (E2).

Verificou-se que a interação entre os fatores foi significativa para as variáveis número e dimensões das células (Tabela 1). O efeito positivo do quinmerac na divisão celular foi evidenciado apenas quando se efetuaram duas aplicações (Figura 1E) ; e na expansão celular, com uma única aplicação (Figura 1F). Para as duas variáveis, o quinmerac teve efeito quadrático tanto para aplicações em E1E2 como em E2 (Figuras 1E e 1F).

Moore (1989) cita que a auxina induz crescimento dos órgãos através da divisão e alongamento celular. Para que ocorra o alongamento celular, é necessária a entrada de água para dentro da célula e a quebra da rigidez da parede celular. $O$ crescimento promovido pela auxina é chamado de crescimento ácido. Segundo Taiz \& Zeiger (2004), supõe-se que a auxina ative ou promova a síntese de novas ATPases na membrana plasmática. A ATPase funciona como uma bomba de próton, promovendo a saída de $\mathrm{H}^{+}$do citoplasma para a parede celular, levando-a à acidificação. A capacidade que os prótons apresentam de causar o afrouxamento da parede celular é mediada por proteínas

A

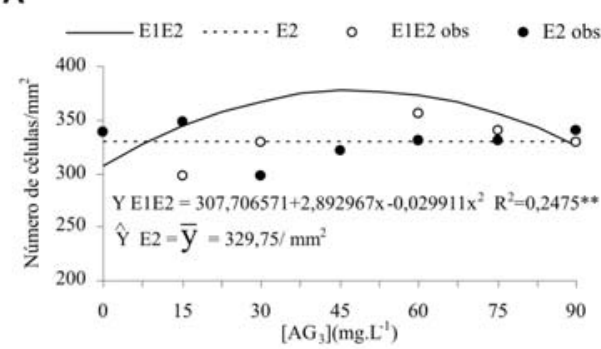

C

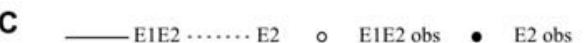

450 Y $\mathrm{Y}$ (1E2) $=343,431524+8,0016 \mathrm{x}-0,267387 \mathrm{x}^{2} \quad \mathrm{R}^{2}=0,2344^{* *}$

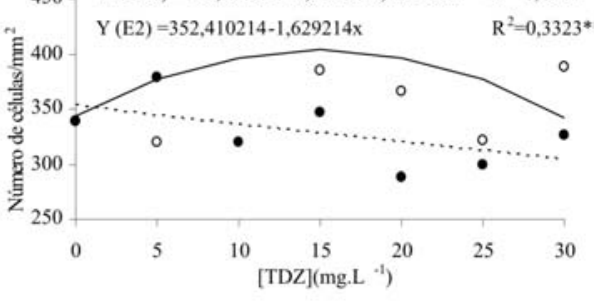

E

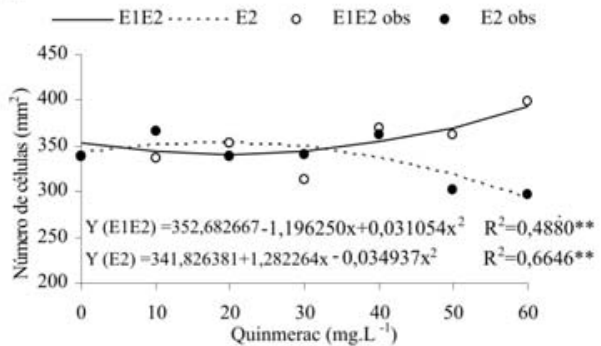

denominadas expansinas. Em valores de pH ácido, as expansinas afrouxam as paredes celulares por quebrar ligações de hidrogênio entre os polissacarídeos da parede. A reconstrução da parede é promovida pela auxina, pela síntese e deposição de polissacarídeos, devolvendo a característica rígida à parede celular.

Quando se efetuou uma única aplicação de quinmerac, em E2, observou-se uma tendência de aumento máximo no número das células até a dose de $18 \mathrm{mg} . \mathrm{l}^{-1}$, seguido de uma diminuição nesses valores. Efeito oposto foi observado com quinmerac aplicado no florescimento e repetido aos 14 dias após (E1E2), em que se verificaram menores reduções no número de células com a dose de $19 \mathrm{mg} . \mathrm{l}^{-1}$, seguido de um aumento nesses valores, com o aumento de doses (Figura 1E).

Para a variável dimensões das células, aplicações de quinmerac diminuíram linearmente as dimensões das bagas, quando aplicado no florescimento e repetido aos 14 dias após, em E1E2; e quadrático, com apenas uma única aplicação, aos 14 dias após o florescimento, em E2 (Figura 1F). Neste caso, observou-se tendência de redução no número de células até a dose de $16 \mathrm{mg} .1^{-1}$, seguido de um aumento nestes valores. Aumentos significativos nas dimensões das células foram observados por Aznar et al. (1995), em tangerinas cv. Fortune tratadas com fenotiol (auxina sintética).
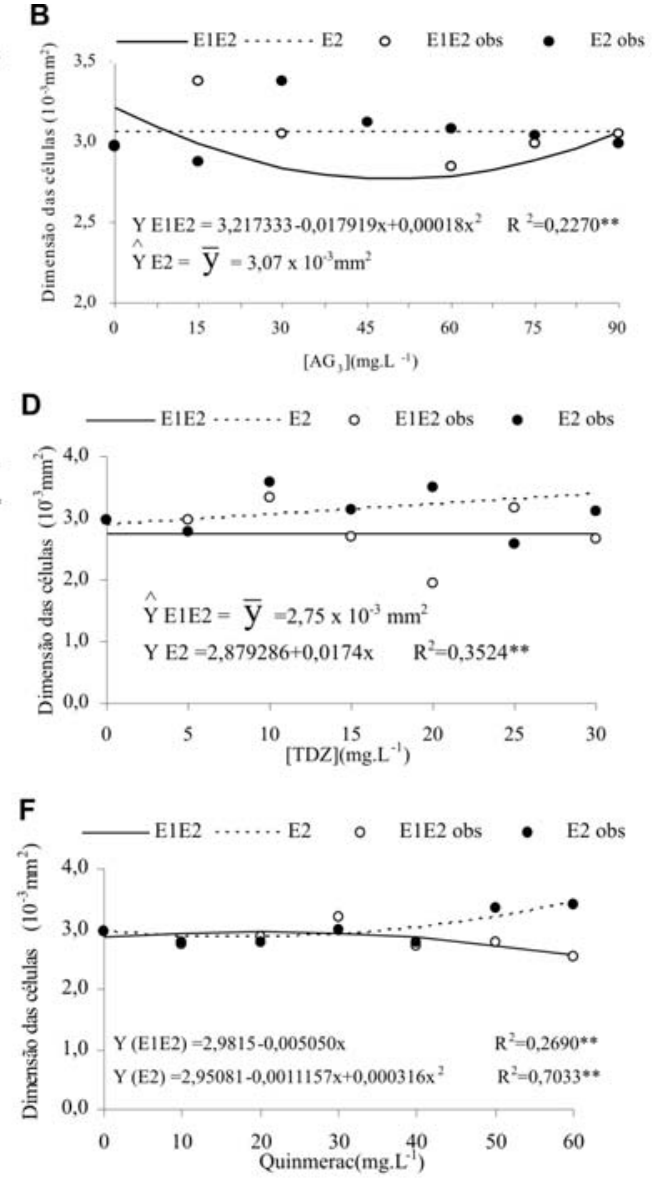

(Ácido giberélico e quinmerac.'=> E1E2= aplicação no florescimento e repetida aos 14 dias após ; E2= aplicação 14 dias após o florescimento. Thidiazuron E1E2'=> quatro dias antes do florescimento e seis dias após; E2= seis dias após a floração.)

FIGURA 1- Número e Dimensões das células $\left(\mathrm{mm}^{2}\right)$ de bagas de uvas 'Niagara Rosada', tratadas com ácido giberélico (A e B), thidiazuron (C e D) e quinmerac (E e F), nas épocas E1E2 e E2. 
TABELA 1- Resumo da análise de variância e aplicação do teste de Tukey e de regressão polinomial para as variáveis: número e dimensões de células das bagas de uvas 'Niagara Rosada' tratadas com ácido giberélico, thidiazuron e quinmerac.

\begin{tabular}{|c|c|c|c|c|c|c|c|c|c|c|c|c|}
\hline \multirow{3}{*}{$\begin{array}{l}\text { Fontes de } \\
\text { Variação }\end{array}$} & \multicolumn{12}{|c|}{ Quadrado médio } \\
\hline & \multicolumn{4}{|c|}{$\mathbf{A G}_{3}$} & \multicolumn{4}{|c|}{ TDZ } & \multicolumn{4}{|c|}{ QUINMERAC } \\
\hline & \multicolumn{2}{|c|}{$\begin{array}{l}\text { Número de } \\
\text { células.mm }{ }^{-2}\end{array}$} & \multicolumn{2}{|c|}{$\begin{array}{c}\text { Dimensões das células } \\
\left(10^{-3} \mathrm{~mm}^{2}\right)\end{array}$} & \multicolumn{2}{|c|}{$\begin{array}{l}\text { Número de } \\
\text { células.mm }{ }^{-2}\end{array}$} & \multicolumn{2}{|c|}{$\begin{array}{c}\text { Dimensões das células } \\
\qquad\left(10^{-3} \mathrm{~mm}^{2}\right)\end{array}$} & \multicolumn{2}{|c|}{$\begin{array}{l}\text { Número de } \\
\text { células.mm }{ }^{-2}\end{array}$} & \multicolumn{2}{|c|}{$\begin{array}{c}\text { Dimensões das células } \\
\left(10^{-3} \mathrm{~mm}^{2}\right)\end{array}$} \\
\hline ÉPOCA & \multicolumn{2}{|c|}{$7451,4533^{\text {ns }}$} & \multicolumn{2}{|c|}{$0,2906^{\text {ns }}$} & \multicolumn{2}{|c|}{$28,213051^{* *}$} & \multicolumn{2}{|c|}{$2,724516^{* *}$} & \multicolumn{2}{|c|}{$8694,5489^{* *}$} & \multicolumn{2}{|c|}{$0,680143^{* *}$} \\
\hline \multicolumn{13}{|l|}{ (EP) } \\
\hline DOSE & \multicolumn{2}{|c|}{$6174,2428 * *$} & \multicolumn{2}{|c|}{$0,2657^{* *}$} & \multicolumn{2}{|c|}{$7,709486^{* *}$} & \multicolumn{2}{|c|}{$0,63768^{* *}$} & \multicolumn{2}{|c|}{$2362,6669^{*}$} & \multicolumn{2}{|c|}{$0,175553^{* *}$} \\
\hline EPxDOSE & \multicolumn{2}{|c|}{$8845,0199^{* *}$} & \multicolumn{2}{|c|}{$0,4323^{* *}$} & \multicolumn{2}{|c|}{$9,914578^{* *}$} & \multicolumn{2}{|c|}{$0,724892^{* *}$} & \multicolumn{2}{|c|}{$4759,6215^{* *}$} & \multicolumn{2}{|c|}{$0,347786^{* *}$} \\
\hline CV (\%) & \multicolumn{2}{|c|}{13,44} & \multicolumn{2}{|c|}{10,98} & \multicolumn{2}{|c|}{6,69} & & 34 & 4 , & 73 & 9 , & \\
\hline & & & & & te de Tukey & para as $\mathrm{m}$ & lias de époc & is de aplicaç & & & & \\
\hline E1E2 & 350, & & & & 19, & & & $5 \mathrm{~b}$ & 357 , & $166 \mathrm{a}$ & 2,8 & $9 \mathrm{~b}$ \\
\hline E2 & 329 , & & & & 18, & & & 4 a & 334, & $76 \mathrm{~b}$ & 3,0 & 1 a \\
\hline & & & & Regres & ão Polinomi & 1 para as d & es de $\mathrm{AG}_{3}$ & TDZ e Quin & merac & & & \\
\hline & & AC & & & & & & & & Quin & merac & \\
\hline & $\begin{array}{l}\text { Núme } \\
\text { células }\end{array}$ & ro de & $\begin{array}{r}\text { Dimensões } \\
\left(10^{-3}\right.\end{array}$ & las células & $\begin{array}{l}\text { Núme } \\
\text { células }\end{array}$ & $\begin{array}{l}\text { ro de } \\
\mathrm{mm}^{-2}\end{array}$ & $\begin{array}{r}\text { Dimensõe } \\
\left(10^{-}\right.\end{array}$ & $\begin{array}{l}\text { das células } \\
\mathrm{mm}^{2} \text { ) }\end{array}$ & $\begin{array}{l}\text { Núm } \\
\text { célula }\end{array}$ & $\begin{array}{l}\text { rode } \\
\mathrm{mm}^{-2}\end{array}$ & $\begin{array}{r}\text { Dimensões } \\
\left(10^{-3}\right.\end{array}$ & $\begin{array}{l}\text { das células } \\
\mathrm{nm}^{2} \text { ) }\end{array}$ \\
\hline & E1E2 & E2 & E1E2 & E2 & E1E2 & E2 & E1E2 & E2 & E1E2 & E2 & E1E2 & E2 \\
\hline Efeito & $1286,414^{\mathrm{ns}}$ & $10,1736^{\mathrm{ns}}$ & $0,0952^{\mathrm{ns}}$ & $0,0010^{\mathrm{ns}}$ & $0,015^{\mathrm{ns}}$ & $7,328 * *$ & $0,018^{\mathrm{ns}}$ & $1,0596^{* *}$ & $6228,3^{* *}$ & $9275,9^{* *}$ & $0,357^{* *}$ & $0,8549^{* *}$ \\
\hline Linear & & & & & & & & & & & & \\
\hline Efeito & & & & & & & & & & & & \\
\hline Quadrático & $19023,0^{* *}$ & $3021,648^{\mathrm{ns}}$ & $0,6873^{* *}$ & $0,2448^{\mathrm{ns}}$ & $10,6466 * *$ & $0,743^{\text {ns }}$ & $0,5138^{\text {ns }}$ & $0,1577^{\mathrm{ns}}$ & $4050,3^{* *}$ & $5126,6^{* *}$ & $0,24723^{\text {ns }}$ & $0,4199^{* *}$ \\
\hline
\end{tabular}

**; *; ns - significativos aos níveis de $1 \% ; 5 \%$ e não-significativo a $5 \%$, pelo Teste de $\mathrm{F}$, respectivamente.

Ácido giberélico e quinmerac.' $=>$ E1E2 = aplicação no florescimento e repetido aos 14 dias após ; E2= aplicação aos 14 dias após o florescimento. Thidiazuron E1E2' $\Rightarrow>$ quatro dias antes do florescimento e seis dias após; E2= seis dias após a floração.

\section{CONCLUSÕES}

1-Aplicações de ácido giberélico induziram aumento do número, mas redução das dimensões das células. A divisão celular foi mais intensa com aplicações de $\mathrm{AG}_{3}$ a $49 \mathrm{mg} \cdot \mathrm{l}^{-1}$. Ocorreu redução no tamanho das células, o que foi compensado pelo maior número de células $/ \mathrm{mm}^{2}$.

2-O número de células foi maior com duas aplicações de thidiazuron, aos quatro dias antes da antese, e repetido aos seis dias após o florescimento, e reduzido com uma única aplicação, aos seis dias após o florescimento. Essa redução foi compensada pelo aumento do tamanho das células.

3-O quinmerac, quando aplicado no florescimento e repetido aos 14 dias após, induziu aumento do número, mas redução do tamanho das células. $\mathrm{O}$ oposto ocorreu quando se efetuou apenas uma aplicação de quinmerac, aos 14 dias após o florescimento.

\section{REFERÊNCIAS}

ANTOGNOZZI E; FAMIANI F; PROIETTI P; TOMBESI A; FERRANTI F; FRENGUELLI G;. Effect of CPPU (cytokinin) treatments on fruit anatomical structure and quality in Actinidia deliciosa. Acta Horticulturae, Wageningen, n.444, p.459-465, 1997.
AZNAR, M.; ALMELA, V.; JUAN, M. EL-OTMANI, M; AGUSTI, $M$. Effect of the synthetic auxin phenothiol on fruit development of 'Fortune' mandarin. Journal of Horticultural Science, Ashford, v. 70, n. 4, p. 617-621, 1995.

BLANK, R.H.; RICHARDSON, A.C.; OSHIMA, K.; HAMPTON, R.E.; OLSON,M.H; DAWSON, T.E.. Effect of a forchlorfenuron dip on kiwifruit fruit size. New Zealand Journal of Crop and Horticultural Science, Wellington, v.20, n.1, p.73-78, 1992.

COSTA, G; CORELLI-GRAPPADELLI, L; BUCCHI, F; PALMER,JW. Studies on apple fruit abscission and growth as affected by cytokinins. Acta Horticulturae, Wageningen, n.557, p. 243-251, 2001.

DAVIES, P.J. The plant hormones: their nature, occurrence, and functions. In:__. Plant hormones and their role in plant growth and development. $2^{\text {nd }}$ ed. Dordrecht: Kluwer Academic Publishers, 1988. p.1-11.

DAYKIN, A.; SCOTT, I. M.; FRANCIS, D.; CAUSTON, D. R. Effects of gibberellin on the cellular dynamics of dwarf pea internode developpement. Planta, Berlin, v.203, n.4, p.526-535, 1997.

GUARDIOLA, J.L.; BARRES, M. T.;ALBERT, C.; GARCIA-LUIS, A. Effects of exogenous growth regulators on fruit development 
in Citrus unshiu. Annals of Botany, London, v. 71, n.2, p. 169$172,1993$.

HENNY, R.J.; FOOSHEE, W.C. Treatment of syngonium 'Maya Red' with thidiazuron in attemp to induce basal branching. Apopka Research Report. Disponível em: <http://www.google.com>. Acesso em: 03 fev. 2002.

HIRATA, N.; HIGANO, R. Efeccts of KT-30 on the growth acceleration of Japanese pears. Proceeding of Japanese Society of Chemical Regulation of Plants, p. 54-55, 1987.

HIRATSUKA, S; MATSUSHIMA, J; KASAI, T; WADA, R; SUZAKI, N. Histological study on skins of grape cultivar 'Olympia' with respect to berry splitting. Journal of the Japanese Society for Horticultural Science, Sakyo-Ku, v.58, n. 3, p. $545-$ $550,1989$.

JOHANSEN, D.A. Plant microtechnique. New York: McGrawHill, 1940. 523p.

JUN, W.; JIAHUANG, Z.; KAI, X.; QINPING, W.; ZHENLIN, W. Effects of exogenous GA3 on fruit development and endogenous hormones in Fujiminori grape. Journal of Fruit Science, New York, v.18., n.4, p. 209-212, 2001.

KANELLIS, A.K.; ROUBELAKIS-ANGELAKIS, K.A. Uva. In: SEYMOUR, G.B.; TAYLOR, J.L.; TUCKER, G.A. (Ed.). Biochemistry of fruit ripening. London: Chapman \& Hall, 1993. p. 189-234.

LUDFORD, P.M. Postharvest hormone changes in vegetables and fruit. In: DAVIES, P.J. (Ed). Plant hormones and their role in plant growth and development. New York: Klewer Academic Publishers, 1987. cap.17.p.574-92.

METIVIER, J.R. Giberelinas. In: Ferri, M.G. Fisiologia vegetal 2. São Paulo: EPU, 1985. p.93-128.

MÉTRAUX, J. P. Gibberellins and plant cell elongation. In: DAVIES, P. J. Plant hormones and their role in plant growth and development. $2^{\text {nd }}$ ed. Dordrecht: Kluwer Academic Publishers, 1988. p. 296-317.

MEYER, M.M.; KERNSH, R. Thidiazuron and in vitro shoot proliferation of Leltius occidentalis L. In: INTERNATIONAL CONGRESS OF PLANT TISSUE AND CELL CULTURE, 6., 1986. Saint Paul, 1986. Abstracts...

MOORE, T.C. Biochemistry and physiology of plant hormones. $2^{\text {nd }}$ ed. New York: Springer-Verlag, 1989. 330 p.

PIRES, E.J.P.; BOTELHO. R.V. Uso de reguladores vegetais na cultura da videira. In: SIMPÓSIO BRASILEIRO SOBRE UVAS DE MESA, 2000, Ilha Solteira. Anais... Ilha Solteira: UNESP / FAPESP, 2001.p.129-147.
RAO, J.; GUO, W.; PENG, L.; ZHANG, J; RAO, J.P.; GUO, W.D.; PENG, L.T.; ZHANG, JK. The effect of CPPU on apple fruit morphological development and endogenous cytokinin content. Scientia Agricultura Sinica, Beijing, v.32, n.5, p. 101-103, 1999.

RODRÍGUEZ, V.A.; MAZZA, S.M.; MARTÍNEZ, G.C; ALVARENGA, L; PÍCCOLI,A.B.; SCHROEDER, M.A. Evaluación del efecto del quinmerac en el segundo año de aplicación y del nitrato de potasio sobre la produtividad de mandarinas clemenules. Corrientes: Universidad Nacional del Nordeste, 2000.

SALISBURY, F. B.; ROSS, C. W. Growth responses to temperature. In: SALISBURY, F. B.; ROSS, C. W. Plant physiology. Belmont : Wadsworth, 1985. p. 409-425.

SARIG, P., ZUTKHI, Y., LISKER, N., SHKELERMAN, Y., BEN ARIE, R. Natural and induced resistance of table grapes to bunch rots. Acta Horticulturae, Wageningen, n.464, p.65-7, 1998.

SASS, J. Botanical microtechnique. Iowa: Iowa College Press, 1951.228p.

SOUSA, J.S.I. Uvas para o Brasil. Piracicaba : FEALQ, 1996. $791 \mathrm{p}$.

SRINIVASAN, C.; MULLINS, M.G. Effects of temperature and growth regulators on formation of anlagen, tendrils and inflorescence in Vitis vinifera L. Annals of Botany, London, v.45, p. 439-446, 1980.

STERN, R.A.; BEN-ARIE, R. ; NERIA, O. ; FLAISHMAN, M. CPPU and BA increase fruit size of 'Royal Gala' (Malus domestica) apple in a warm climate. Journal of Horticultural Science and Biotechnology, Valência, v. 78, n.3, p.297-302, 2003.

TAIZ, L \& ZEIGER, E. Fisiologia vegetal. 3. ed. Porto Alegre: Artmed, 2004. 720p.

VALIO, I.F.M. Auxinas. In: Ferri, M.G. Fisiologia Vegetal 2. São Paulo: EPU, 1985. p.39-72.

WAREING, F.R.S , PHILLIPS, I.D.J. The control of growth and differentiation in plants. $5^{\text {th }}$ ed. New York: Pergamon Press, 1976. 303 p.

WOOLLEY, D. J.; LAWES, G. S.; CRUZ-CASTILLO, J. G.; CURRIE, M. B. Cell activity and fruit size. Rotorua: New Zealand Kiwifruit Marketing, 1992. p.28-31. (Special Publication, 4).

WU, J; ZHONG, J H; XU, K; WEI, QP; WEI, ZL. Effects of exogenous GA3 on fruit development and endogenous hormones in Fujiminori grape. Journal of Fruit Science, New York,v.18, n.4, p. 209-212, 2001. 